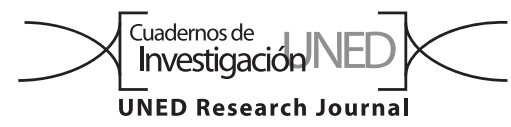

\title{
Ecosistemas marinos antárticos después del rompimiento de barreras de hielo
}

\author{
Maria Vernet ${ }^{1}$ y Mattias R. Cape ${ }^{2}$ \\ 1. Instituto Scripps de Oceanografía, La Jolla, California, Estados Unidos de Norteamérica; mvernet@ucsd.edu \\ 2. Universidad de Washington, Seattle, Washington, Estados Unidos de Norteamérica; mcape@uw.edu
}

Recibido 24-IX-2018 • Corregido 21-XII-2018 • Aceptado 14-I-2019

\begin{abstract}
Antarctic marine ecosystems after ice barriers breaking off. Widespread thinning and retreat of ice shelves along the margins of Antarctica provide a unique opportunity to understand the evolution of Antarctic coastal ecosystems and the consequences of abrupt global change in high latitudes. As dark environments isolated from the atmosphere, the under-ice-shelf ecosystems remain mostly unknown. After ice shelf breakup there is an opportunity to study the evolution of the coastal ecosystem exposed to the atmosphere after millennia. One of the more active regions is the Larsen Ice Shelf, on the NW of the Weddell Sea. After the ice shelf breakup, phytoplankton grow in the presence of light; primary production rates observed are amongst the highest in Antarctica. Zooplanktonic and benthic communities in the marine food web can feed on this newly synthesized carbon. In this way, regions previously unproductive are now able to absorb carbon dioxide and contribute to its absorption by the ocean.
\end{abstract}

Key words: ice shelf, Antarctica, ecosystem, phytoplankton, sea ice, foehn winds.

\section{EL ECOSISTEMA ANTÁRTICO COSTERO ASOCIADO A LAS BARRERAS DE HIELO}

La Antártida es un continente de extremos climáticos, con bajas temperaturas y extremos en iluminación, desde permanente oscuridad en los meses de invierno a 24 horas de luz en el verano. Los organismos marinos se han adaptado a esta variabilidad en las condiciones ambientales y las características de adaptación comparten cierta similitud con organismos de agua dulce en zonas de alta latitud y altitud (Russell, 2000). La combinación de los eventos climáticos con la orografía y las condiciones oceánicas a ambos lados de la Península Antártida provee un ejemplo clásico de esta variabilidad (Fig. 1a). Al
RESUMEN: Los desprendimientos en las barreras de hielo antárticas proveen una oportunidad única para entender la evolución de ecosistemas costeros y las consecuencias de cambio global abrupto en altas latitudes. Los ecosistemas desarrollados debajo de las barreras de hielo han estado aislados de la atmósfera por miles de años y permanecen en gran medida desconocidos hasta el presente. Una de las regiones más activas al respecto es el este de la Península Antárctica donde varias barreras de hielo han ido desapareciendo en los últimos 100 años, en un gradiente de norte a sur. El evento más reciente fue el desprendimiento de un témpano gigantesco de $5.800 \mathrm{Km}^{2}$ de la barrera Larsen C, denominado A68, el 12 de julio de 2017. Una vez que la barrera de hielo desaparece, las aguas subyacentes se encuentran expuestas a la atmósfera en condiciones para sostener crecimiento del fitoplancton. El carbono orgánico producido puede a su vez alimentar zooplancton y bentos y mantener una trama trófica marina. De esta manera, áreas previamente no productivas pueden ahora absorber dióxido de carbono y contribuir a la absorción del mismo por aguas oceánicas.

Palabras claves: barreras de hielo, Antártida, ecosistema, fitoplancton, vientos mistrales. 

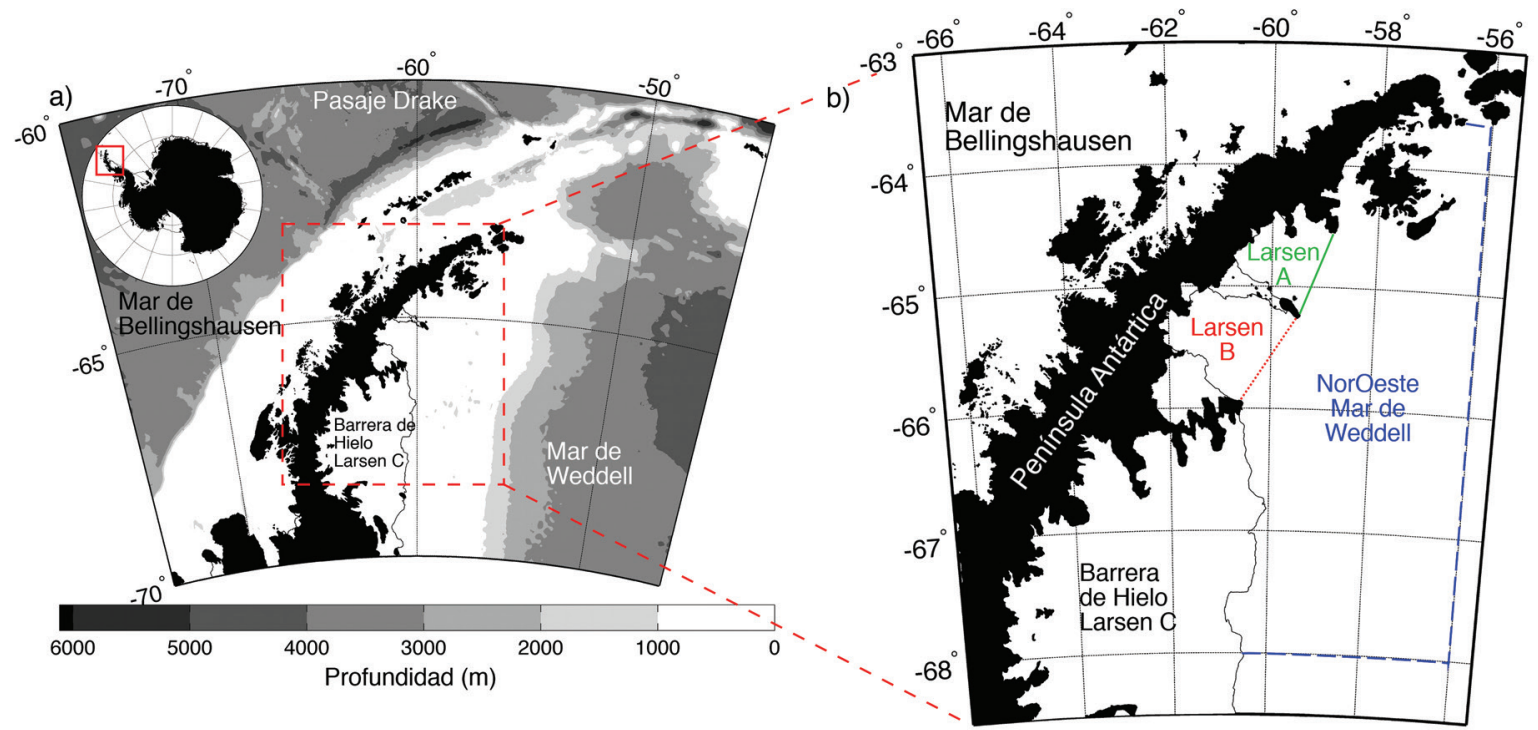

Fig. 1. a) La Antártida incluyendo la Península Antártica. El Océano Antártico, rodeando el continente, se define generalmente al sur de latitud $60^{\circ} \mathrm{S}$ o al sur del Frente Polar, que separa aguas subantárticas de las antárticas con un gradiente de temperatura del agua de mar de hasta $5^{\circ} \mathrm{C}$ en una distancia menor que $100 \mathrm{Km}$. b) El área de Larsen al este de la península en el noroeste del Mar de Weddell. La plataforma continental tiene una extensión de 200-300Km con una profundidad promedio de 500 a $600 \mathrm{~m}$ (Cape, Vernet, Kahru \& Spreen, 2014).

hacia el sur y luego hacia el oeste y finalmente hacia el norte, siguiendo el contorno de la costa (Orsi, Nowlin \& Whitworth, 1993). El hielo marino puede entonces acumularse y crecer por más de 1 ó 2 años, dando como resultado un hielo grueso y deformado. En presencia de una cubierta de nieve, el hielo de mar limita la transmisión de luz a las aguas superficiales, impidiendo el crecimiento de fitoplancton (Perovich, 1990; Fig. 2).
Durante el verano austral de 2001-2002, las condiciones ambientales facilitaron la desintegración de la barrera de hielo que había perdurado por más de 10000 años en la Bahía Larsen B (Domack et al., 2005). Temperaturas atmosféricas más cálidas que lo normal causaron fisuras en la barrera de hielo y derritieron la superficie. El agua penetró por las fisuras, extendiéndolas, hasta llegar a la base, rompiendo así la masa de hielo (Fig. 3). Este hielo

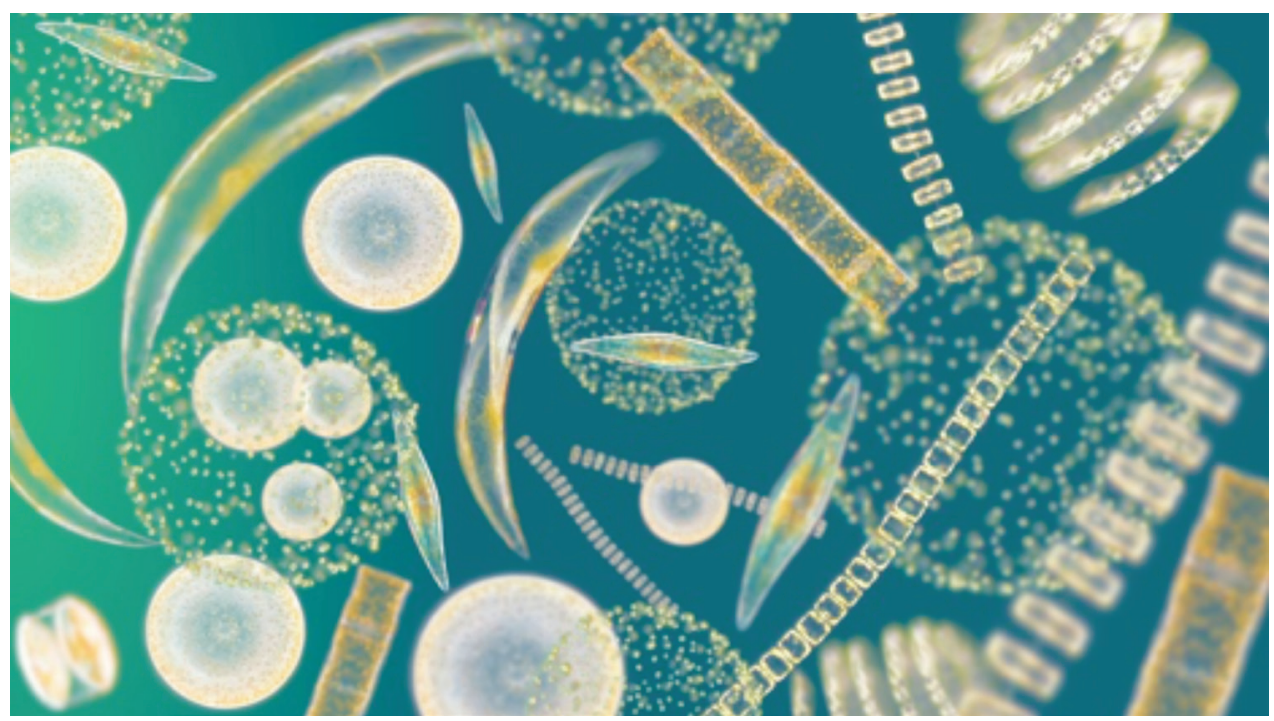

Fig. 2. El fitoplancton antártico se caracteriza por la abundancia de diatomeas, microalgas unicelulares envueltas en una estructura de vidrio (sílice) presentando una gran diversidad de formas y tamaños. (Crédito: Wikipedia commons) 


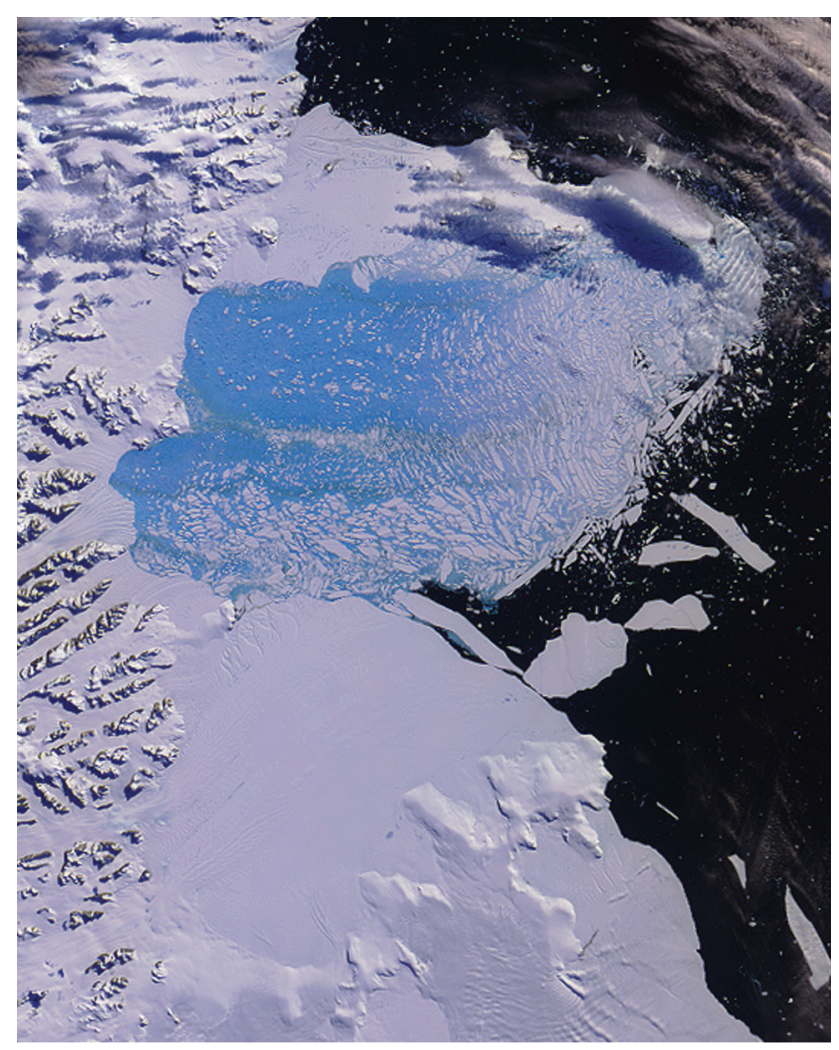

Fig. 3. Rompimiento de la barrera de hielo de Larsen B en el verano austral de 2001-2002 (Scambos, Hulbe \& Fahnestock, 2003). El hielo de color azulado indica desintegración mientras que el hielo blanco representa las zonas no afectadas. A la izquierda se observan rocas de la Península Antártica mientras que el color negro representa aguas abiertas.

se distribuyó en el mar en forma de millones de témpanos de diversos tamaños, desde enormes trozos de decenas de kilómetros de largo hasta otros más pequeños de unos pocos de metros. Estos témpanos se mezclaron con el hielo marino que deriva hacia el norte hasta llegar a aguas abiertas. El rompimiento de la barrera Larsen B siguió un patrón de procesos de deshielo iniciados en 1947, en el estrecho Príncipe Gustavo, cerca de la punta de la península. El rompimiento de la barrera de hielo en Larsen A ocurrió en 1996, después de 30 años de desintegración paulatina de los bordes exteriores de la barrera (Ferrigno et al., 2008). Asimismo, los bordes de la barrera Larsen B iniciaron una retracción en 1961. Después de varios avances y retrocesos del borde, el rompimiento final llegó en 2002. Más recientemente, en 2017, un gran témpano se desprendió en Larsen C, más al sur, iniciando lo que puede llegar a ser el lento proceso de retroceso de la barrera.

Sin la presencia de la barrera de hielo, las aguas de la región costera se exponen a la atmósfera y a la luz del sol, permitiendo así el crecimiento de microalgas y la producción de carbono orgánico que sirve de alimento para animales y bacterias. Antes del rompimiento, el ecosistema bajo el hielo se caracteriza por una baja abundancia y diversidad de organismos. Es poco lo conocido de estos ambientes, debido a su inaccesibilidad ya que solamente perforaciones en la barrera de hielo o robots pueden entrar debajo de una barrera de hielo, a cientos de metros de profundidad. En ausencia de fitoplancton local, una variedad de fuentes de carbono puede alimentar comunidades desarrolladas en la oscuridad. En el Mar de Ross, la muerte de peces mantiene crustáceos móviles que se alimentan de cadáveres, anfípodos e isópodos y también copépodos y algunos peces (Bruchhausen et al., 1979; Lipps, Ronan \& DeLaca, 1979). Cuando el carbono suspendido entra por debajo de la barrera por medio de las corrientes, una comunidad sésil puede establecerse: briozoos, equinodermos y esponjas, como se encontró debajo de la barrera de hielo Amery (Riddle, Craven, Goldsworthy \& Carsey, 2007). Fotografías submarinas sugieren que debajo de la barrera del Larsen B, la producción local puede haber sido quimio-autotrófica, con el gas metano, presuntamente originado de las rocas, subiendo a superficie y alimentando bacterias anaeróbicas y almejas "vesicomyds" (Domack et al., 2005).

El rompimiento de estas barreras origina una oportunidad única para estudiar el desarrollo de ecosistemas antárticos costeros. ¿Cómo es la tasa o velocidad de la evolución de los organismos que componen los ecosistemas bajo el hielo? ¿Los organismos ectotérmicos tendrán una tasa metabólica baja, acorde a la temperatura? ¿Tienen los distintos componentes del sistema una evolución paralela o existen factores que afectan la evolución de cada componente de manera diferenciada? Empleando al fitoplancton de la región Larsen como ejemplo este artículo describirá estudios que contestan algunas de estas preguntas.

\section{ALTA ABSORCIÓN DE DIÓXIDO DE CARBONO POR LA PRODUCTIVIDAD PRIMARIA DEL FITOPLANCTON DESPUÉS DEL ROMPIMIENTO DE BARRERAS DE HIELO}

Una vez que la barrera de hielo desaparece y los témpanos se alejan de las bahías, el agua de mar entra en contacto con la atmósfera, con posibilidad de producir carbono orgánico a través de la fotosíntesis del fitoplancton. Las microalgas planctónicas aparecen en esas aguas transportadas por las corrientes, invadiendo el nuevo ambiente en un período relativamente rápido. Su crecimiento será posible en el próximo verano. Si las 

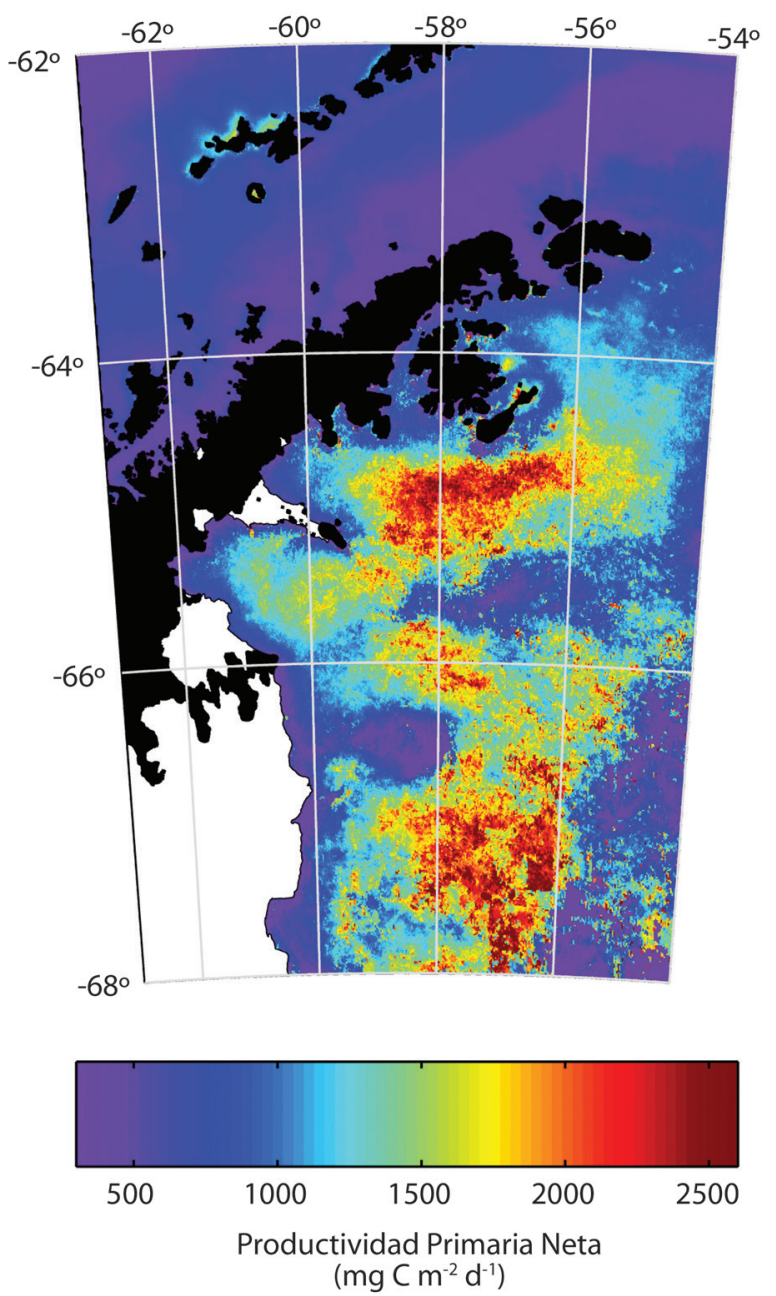

Fig. 4. Distribución de la productividad primaria promedio (1997-2011), o la tasa de síntesis de carbono orgánico por fotosíntesis, en las aguas del noroeste Mar de Weddell después del rompimiento de las barreras de hielo de Larsen A y B (Cape et al., 2014), medidas en unidades de 500-2500mg diarios de carbono por metro cuadrado. Las zonas indicadas en rojo muestran la más alta concentración de fitoplancton con la habilidad de producir más de $2 \mathrm{~g}$ de carbono diarios por metro cuadrado de superficie de mar.

condiciones ambientales son adecuadas existe la posibilidad de un crecimiento local importante (Bertolín \& Schloss, 2009).

Basados en imágenes satelitales se puede determinar que el fitoplancton en las bahías de Larsen A y B después del rompimiento de las barreras presenta una distribución característica, con máxima concentración a 100-150 kilómetros de distancia de la costa (Fig. 4). Los valores de productividad son similares a las más altas productividades del Océano Antártico (Smith, Marra, Hiscock \& Barber,
2000; Bertolín \& Schloss, 2009 ). Esta acumulación alta de fitoplancton sugiere un balance positivo entre el crecimiento de microalgas y los mecanismos de pérdida tales como el forrajeo por parte del zooplancton o advección lateral que transporta el plancton a otras localidades. Es así como la región de Larsen después del rompimiento de las barreras de hielo es una fuente importante de absorción de dióxido de carbono y de producción de carbono orgánico.

La presencia de fitoplancton en esta área es muy variable. Si se mide su abundancia mediante la concentración del pigmento fotosintético clorofila $a$ (clo $a$ ), considerada un indicador de la biomasa de fitoplancton, hay registros de hasta $8 \mathrm{mg} \mathrm{m}^{-3}$ (por ejemplo, en el año 2005) y otros en que los satélites no detectan clo $a$ entre octubre y marzo, el período de luz (por ejemplo, en los años 2001 ó 2010) (Fig. 5a). El promedio entre los años 2000 y 2010 en la Bahía Larsen B fue de $1 \mathrm{mg}$ clo $a \mathrm{~m}^{-3}$.

¿A qué se debe esta alta variación interanual del fitoplancton? Observaciones de imágenes satelitales que determinan la abundancia de hielo marino indican que las bahías Larsen están despojadas de hielo marino en los años con fitoplancton (Fig. 5b). Los satélites necesitan que la cobertura de hielo marino sea inferior al 15\% de la superficie para poder cuantificar la concentración de clo $a$. Es posible que el fitoplancton sobreviva en concentraciones de hielo mayores del 15\% pero los satélites no pueden detectarla. La productividad del fitoplancton puede entonces ser mayor que lo indicado en Figuras 4 y 5 . Solamente el trabajo de campo, con buques oceanográficos, puede darnos una información más acertada. Sin embargo, el acceso a esta región es muy limitada y los barcos no pueden entrar a las bahías en condiciones de cobertura de hielo mayores del $50 \%$. La alta variabilidad interanual de productividad se debe entonces a la alta variabilidad en la distribución de aguas abiertas que, como se observa en la Figura $5 b$, se presenta solamente en 6 de cada 10 veranos. Estas condiciones son representativas de lo que sucede en todo el oeste del Mar de Weddell, con lo que esta región contribuye significativamente a la productividad antárctica (Cape et al., 2014).

\section{FACTORES CLIMÁTICOS QUE CONTROLAN LA DISTRIBUCIÓN DEL FITOPLANCTON}

Del idioma ruso, el término "polynya" describe un área oceánica de la zona costera antártica libre de hielo marino. Los procesos responsables de la formación de estas estructuras son el derretimiento de hielo, generalmente en localidades de aguas relativamente calientes, con temperaturas por arriba del punto de congelamiento del 


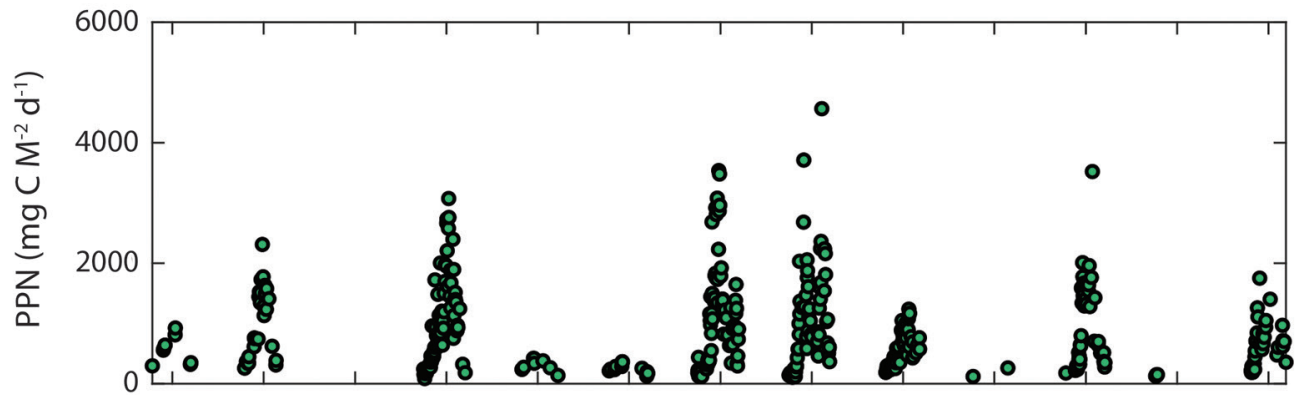

B

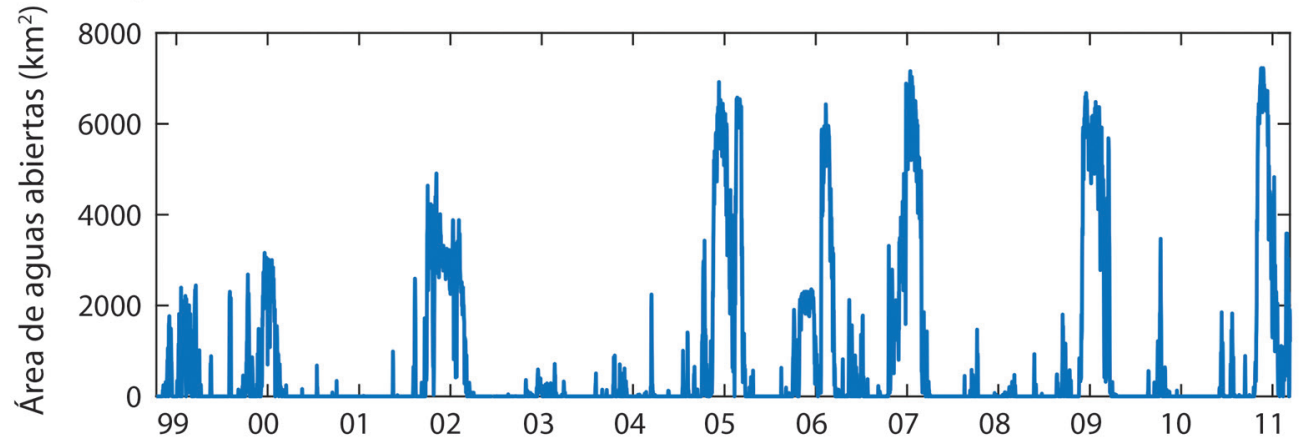

Fig. 5. Abundancia de fitoplancton, indicado por la tasa de productividad primaria en aguas superficiales de la Bahía Larsen B, entre los años 1999 y 2011. A) Los puntos verdes indican productividad primaria a lo largo del año, en unidades de microgramo de carbono por metro cuadrado por día. B) Área del océano descubierta (sin hielo) en kilómetros cuadrados.

agua del mar (-1,84 grados centígrados). También se encuentran en localidades de fuertes vientos costeros del Sur que introducen el hielo ya formado hacia aguas profundas, permitiendo la formación de más hielo; este tipo de polynya es considerada una pequeña fábrica de hielo marino. Finalmente, un tercer proceso es la presencia de vientos relativamente más cálidos, con temperaturas por encima del punto de congelamiento, que empujan el hielo hacia aguas profundas, sin permitir la formación de nuevo hielo.

Las polynyas en la Bahías Larsen están formadas por vientos mistrales (o foehn) que bajan de las montañas de la Península Antártica hacia el Mar de Weddell. Su alta temperatura, a veces mayor de $10^{\circ} \mathrm{C}$, y su alta velocidad, de más de $40 \mathrm{~m} \mathrm{~s}^{-1}$, producen no sólo el derretimiento del hielo marino sino también su desplazamiento a aguas más profundas, dejando así una zona de aguas abiertas cerca de la costa, o polynya. Analizando datos atmosféricos, tomados por torres con sensores emplazados sobre glaciares y zonas costeras aledañas, es posible determinar la frecuencia de los vientos mistrales. Si se define un evento mistral a través de la presencia de vientos cálidos y secos por un periodo de 6 horas o más, se puede observar que durante el invierno y la primavera, desde junio a octubre, más del $40 \%$ de los días llegan a tener períodos de vientos mistrales (Fig. 6a, Cape, 2014). En comparación, el verano y otoño son más calmos. Sin embargo, y como se puede anticipar debido a la variabilidad en aguas abiertas (Figura 5b), los vientos mistrales también presentan una alta variabilidad en el tiempo. Esto está demostrado por las barras alrededor de la línea promedio (Figura 6a) que indican valores mínimos y máximos de eventos mistrales encontrados para cada mes del año. Es así que, en el mes de octubre, con un promedio de $42 \%$ de días con vientos mistrales, hay años de hasta $60 \%$ de días con vientos mistrales mientras que otros presentan la mitad, alrededor del $35 \%$. Que estos vientos son los responsables de la presencia de aguas abiertas está demostrado por la alta correlación entre la variabilidad de días con vientos mistrales y aguas abiertas (Fig. 6b; Cape, 2014).

Los vientos mistrales que se observan en la zona Larsen son parte de los vientos que circulan alrededor del continente antártico. Su presencia es constante y se los denomina "vientos del oeste". Estos vientos son en general fríos y húmedos. Cuando el viento del oeste se topa con las montañas de la Península Antártica, se desvía hacia el norte o sube a una altitud que le permite cruzar la península. Al bajar hacia el este, por descompresión adiabática, el viento se calienta, pierde humedad y obtiene velocidad, convirtiéndose así en un viento mistral. La variabilidad de estos vientos antárticos con respecto a su 

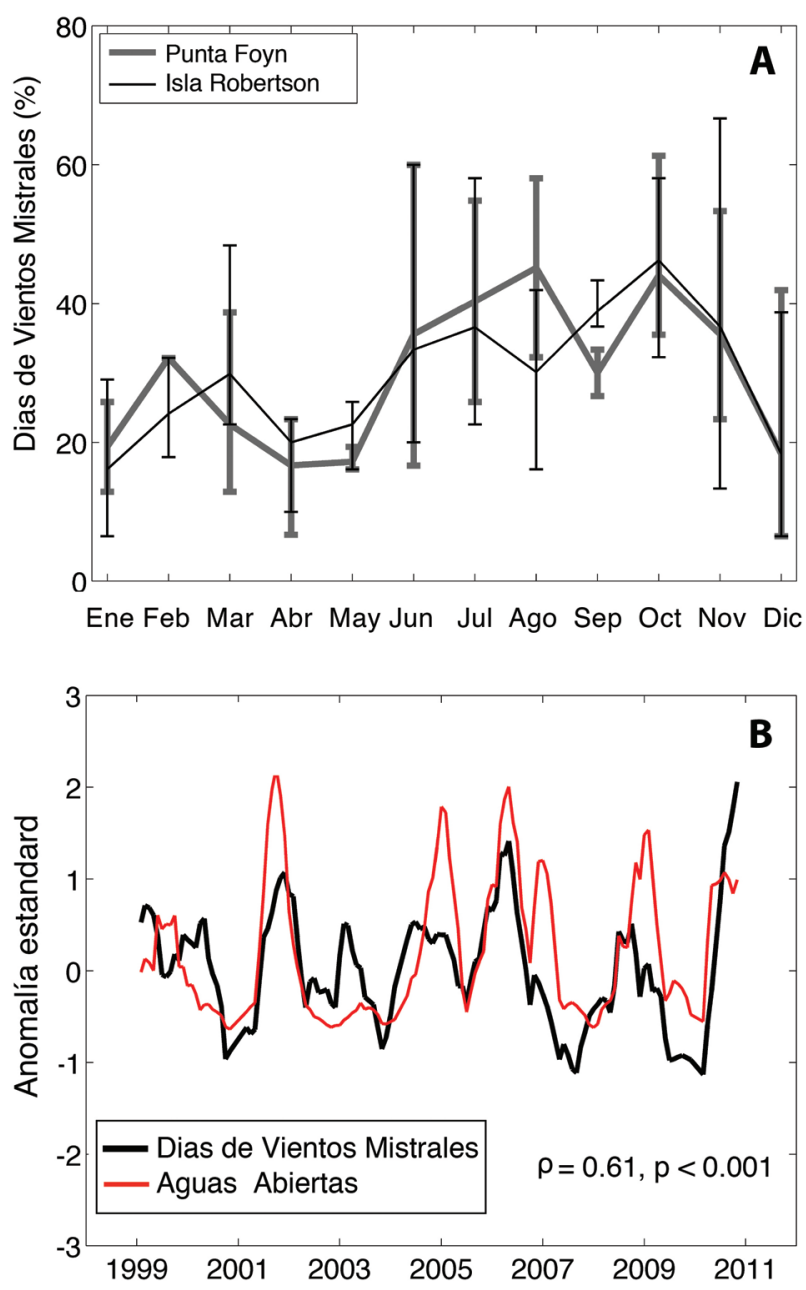

Fig. 6. Características de los vientos mistrales en dos localidades de la bahía Larsen B y su efecto en el océano. A) Promedio mensual de días con vientos mistrales (líneas negras) y el error de medición (líneas verticales) indicando la variabilidad observada en cada mes (Cape, 2014). B) Variabilidad inter anual de los vientos mistrales (línea negra) en comparación con la variabilidad inter anual de aguas abiertas (línea roja) (Cape, 2014).

intensidad está relacionada a eventos atmosféricos del hemisferio sur. Estos vientos aumentan en condiciones de mayor gradiente de presión atmosférica entre zonas tropicales y antárticas (Cape, Vernet, Skvarca, Marinsek, Scambos \& Domack, 2015).

\section{EVOLUCIÓN DEL ECOSISTEMA MARINO ANTÁRTICO COSTERO}

Un ecosistema antártico costero maduro, desarrollado por miles de años, presenta una diversidad alta de fitoplancton, zooplancton, peces, aves (por ejemplo, pingüinos) y mamíferos marinos (por ejemplo, ballenas y focas). Todos estos organismos se alimentan de fitoplancton en forma directa o indirecta, a través de la trama, o maraña, trófica. Organismos bentónicos, en el fondo del mar, también necesitan alimento. La colonización bentónica en las bahías Larsen después del rompimiento de las barreras de hielo se debe a la presencia de alimento nuevo, originado por el carbono orgánico que sedimenta. Bacterias y animales intersticiales que viven entre los granos de sedimento, o animales más grandes que viven sobre el sedimento, todos dependen de esta transferencia de carbono desde la superficie del océano (Fig. 7). El carbono producido por el fitoplancton local es transferido a los organismos del fondo principalmente a través de dos procesos: el hundimiento de células de fitoplancton y bacterias y la producción de partículas fecales del zooplancton que a su vez se combinan en agregados o nieve marina, la mayor fuente de sedimentación de materia orgánica particulada. El carbono que llega al fondo se deposita sobre el sedimento. Organismos bentónicos sésiles han empezado a colonizar esta región como respuesta al aumento de nuevas fuentes de carbono (Gutt et al., 2013).

Como consecuencia de la variabilidad en la abundancia de fitoplancton, es posible predecir una gran variabilidad interanual en la fuente de carbono para las comunidades bentónicas. Los modelos de sedimentación de carbono a profundidad se basan en las estimaciones de productividad en aguas superficiales. Es así que se predice que alrededor del $25 \%$ del carbono fijado, llegará al bentos (Cape, 2014) en los años con producción primaria elevada. Si se mide la abundancia de clo $a$ en sedimentos superficiales, indicador de fitoplancton que ha llegado a sedimentar, es posible observar 5 veces más clo $a$ en las regiones de alta abundancia de fitoplancton (Fig. 4), a 140Km de la costa que en localidades a $10 \mathrm{Km}$ de la costa. Esta diferencia se observa también en las fotografías de fondo, donde un color amarillento coincide con alta clo $a$ y un color azulado en sedimentos bajos en clo $a$ (Fig. 6).

Varias conclusiones de importancia para la ecología de la zona costera antártica se vislumbran de los estudios acerca de la evolución de los ecosistemas después del rompimiento de una barrera de hielo:

1. Se incrementa la absorción de dióxido de carbono por el océano a consecuencia de la mayor productividad primaria en aguas previamente cubiertas de hielo.

2. La nueva producción local de carbono orgánico por fitoplancton permite la invasión de organismos planctónicos y bentónicos. 


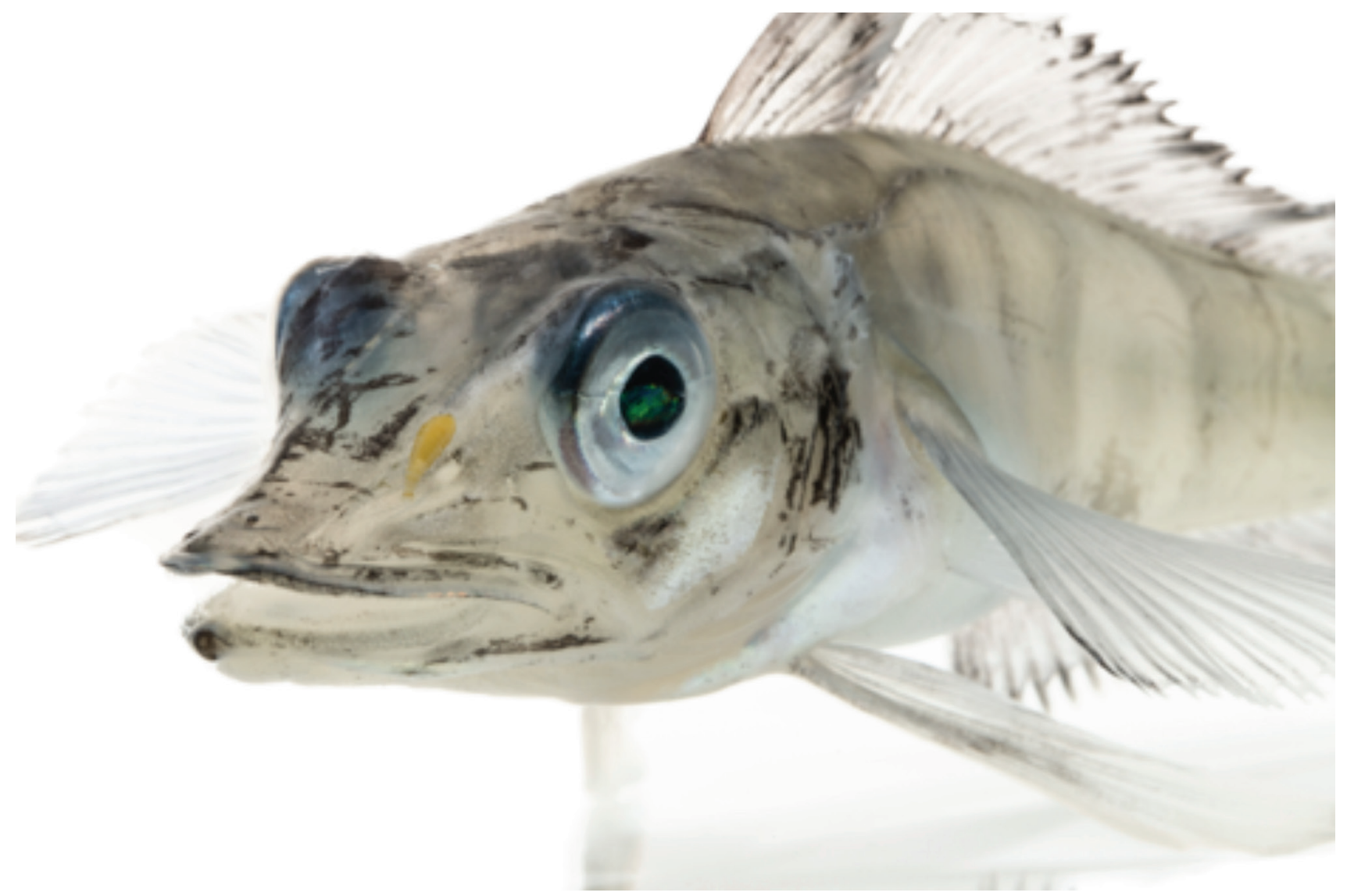

Fig. 7. Pez bentónico recogido en fiordos antárcticos que se alimenta de los animales bentónicos detritívoros (fotografía de Maria Stenzel).

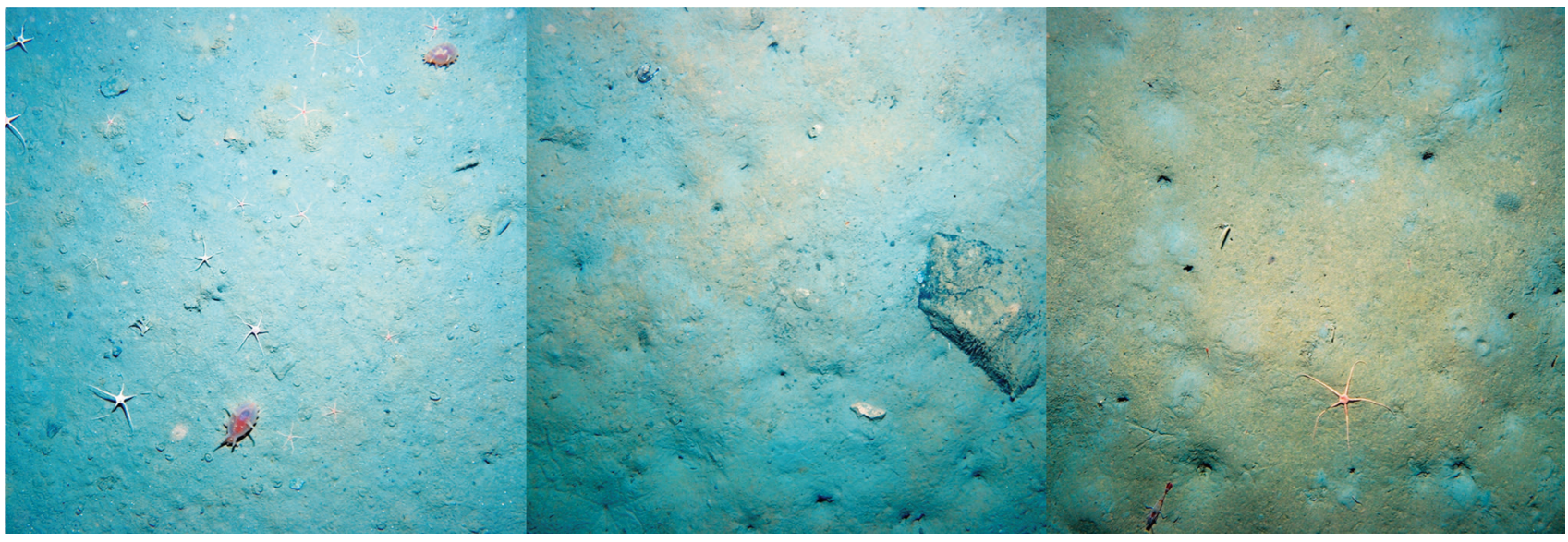

Fig. 8. La sedimentación de carbono orgánico desde la superficie del océano a profundidad, en las bahías Larsen, puede medirse por el color: poco carbono fitoplanctónico a $10 \mathrm{Km}$ de la costa se visualiza como un sedimento gris-azulado (foto hacia la izquierda), intermedio y alta sedimentación con color amarillento (hacia la derecha). El color del sedimento coincide con la distribución de productividad primaria (Fig. 5). 
3. El nuevo sistema funciona como una polynya, con aguas abiertas rodeadas de hielo marino. Este sistema es muy variable en el tiempo, sugiriendo que los animales dependientes de la producción local de carbono están adaptados tanto a condiciones de escasez como de abundancia.

4. Este nuevo sistema está controlado por las condiciones atmosféricas del hemisferio sur que influyen en la variabilidad del viento del oeste y la frecuencia de los vientos mistrales en esta región al este de la Península Antártica.

\section{AGRADECIMIENTOS}

Los autores agradecen la invitación por la Universidad de Costa Rica para participar en el Primer Simposio Latino Americano de Cambio Global en San José de Costa Rica, en agosto 2017. También agradecen a los colaboradores del proyecto LARISSA, en particular los Drs. Craig R. Smith y Michael McCormick por ayuda en el campo e intercambio de ideas; y a los técnicos, voluntarios que hicieron posible la colección de muestras científicas y análisis de datos. Igualmente se agradece la financiación por la Agencia Nacional de Ciencia de los Estados Unidos de Norte América (NSF) a M. Vernet, proyecto ANT-0732983 y beca DGE-1144086 a M.R. Cape y también beca de la Agencia Nacional del Espacio (NASA) NNX12AN48H a M.R. Cape.

\section{REFERENCIAS}

Bertolin, M. L., \& Schloss, I. R. (2009).Phytoplankton production after the collapse of the Larse A Ice Shelf, Antarctica. Polar Biology, 32, 1435-1446.

Bruchhausen, P. M., Raymond, J. A., Jacobs, S. S., DeVries, A. L., Thorndike, E. M., \& DeWitt, H. H. (1979). Fish, Crustaceans, and the Sea Floor Under the Ross Ice Shelf. Science, 203(4379), 449-451.

Cape, M. R. (2014). Impacts of atmosphere - ice - ocean interactions on phytoplankton along the coastal Antarctic Peninsula (PhD thesis). University of California San Diego, EE.UU.

Cape, M. R., M. Vernet, M. Kahru, G. Spreen (2014). Polynya dynamics drive primary production in the Larsen $A$ and B embayments following ice shelf collapse. Journal of Geophysical Research-Oceans, 119(1), 572-594.
Cape, M. R., Vernet, M., Skvarca, P., Marinsek, S., Scambos, T., \& Domack, E. (2015). Foehn winds link climate-driven warming to ice shelf evolution in Antarctica. Journal of Geophysical Research: Atmospheres, 120(21), 11-037. DOI: 10.1002/2015JD023465

Cook, A. J., \& Vaughan, D. G. (2010). Overview of areal changes of the ice shelves on the Antarctic Peninsula over the past 50 years. The Cryosphere, 4(1), 77-98.

Domack, E., Duran, D., Leventer, A., Ishman, S., Doane, S., McCallum, S., ... \& Prentice, M. (2005). Stability of the Larsen $B$ ice shelf on the Antarctic Peninsula during the Holocene epoch. Nature, 436(7051), 681.

Ferrigno, J. G., Cook, A. J., Mathie, A. M., Williams, R. S. J., Swithinbank, C., Foley, K.,M., Thomson, A. J., \& Sievers, J. (2008). Coastal-change and glaciological map of the Larsen Ice Shelf area, Antarctica: 1940-2005. US Geological Survey Geologic Investigations Map Series, Map I-2600-B, with 28p pamphlet, EE. UU.

Gutt, J., Cape, M., Dimmler, W., Fillinger, L., Isla, E., Lieb, V., ... \& Pulcher, C. (2013). Shifts in Antarctic megabenthic structure after ice-shelf disintegration in the Larsen area east of the Antarctic Peninsula. Polar Biology, 36(6), 895-906. DOI:10.1007/s00300-013-1315-7.

Lipps, J. H., Ronan, T. E., \& DeLaca, T. E. (1979). Life below the Ross ice shelf, Antarctica. Science, 203(4379), 447-449.

Orsi, A. H., Nowlin Jr, W. D., \& Whitworth III, T. (1993). On the circulation and stratification of the Weddell Gyre. Deep Sea Research Part I: Oceanographic Research Papers, 40(1), 169-203.

Perovich, D. K. (1990) Theoretical estimates of light reflection and transmission by spatially complex and temporally varying sea ice covers. Journal of Geophysical Research, 95, 9557-9567.

Riddle, M. J., Craven, M., Goldsworthy, P. M., \& Carsey, F. (2007). A diverse benthic assemblage $100 \mathrm{Km}$ from open water under the Amery Ice Shelf, Antarctica. Paleoceanography, 22(1), PA1204. DOI:10.1029/2006PA001327

Russell, N. J. (2000) Toward a molecular understanding of cold activity of enzymes from psychrophiles. Extremophiles, 4, 83-90.

Scambos, T., Hulbe, C., \& Fahnestock, M. (2003). Climate-induced ice shelf disintegration in the Antarctic Peninsula. Antarctic Peninsula Climate Variability: Historical and Paleoenvironmental Perspectives. Antarctic Research Series, 79, 79-92.

Smith Jr, W. O., Marra, J., Hiscock, M. R., \& Barber, R. T. (2000). The seasonal cycle of phytoplankton biomass and primary productivity in the Ross Sea, Antarctica. Deep Sea Research Part II: Topical Studies in Oceanography, 47(1516), 3119-3140. 